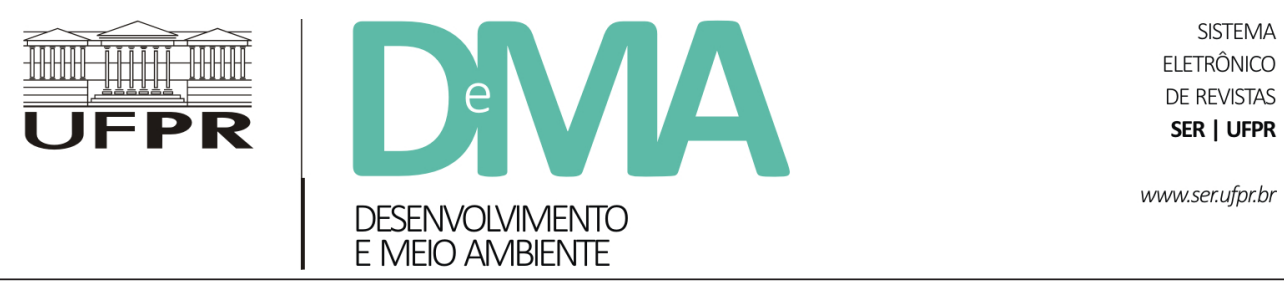

\title{
Evaluación de amenazas tecnológicas en la ciudad de Paranaguá/PR, Brasil
}

\section{Avaliação de ameaças tecnológicas na cidade de Paranaguá/PR, Brasil}

\section{Evaluation of Technological Threats at the City of Paranaguá/PR, Brazil}

\author{
Daniela TORRISI ${ }^{1 *}$, Eduardo Vedor de PAULA ${ }^{1}$, Carlos Augusto WROBLEWSKY $^{1}$ \\ ${ }^{1}$ Universidade Federal do Paraná (UFPR), Curitiba, PR, Brasil. \\ *E-mail de contacto: torrisi608@gmail.com
}

Artículo recibido el 23 de marzo, 2016, versión final aceptada el 30 de mayo, 2017.

RESUMEN: La reducción de riesgo de desastre está ganando protagonismo en el campo de las ciencias ambientales, aportando diagnósticos territoriales relevantes. En este sentido, el objetivo del presente trabajo es analizar y evaluar los niveles de amenaza tecnológica vinculados al almacenamiento de productos peligrosos en la ciudad de Paranaguá. La metodología implementada se basa en una propuesta que toma como referencia a la legislación española (Reglamento de Actividades Molestas, Insalubres, Nocivas y Peligrosas de 1961), a la Organización de las Naciones Unidas (ONU), y por último a la Agencia Nacional de Transportes Terrestres (ANTT) de Brasil. El análisis será realizado a partir del SIG ArcGIS 10.1, con el comando buffers, considerando a la distancia como factor de exposición. A partir de la aplicación de esta metodología, se concluye que un total de $84,75 \mathrm{~km}^{2}$ están bajo amenazas tecnológicas y más de 124.000 personas serían afectadas ante un evento.

Palabras claves: amenaza tecnológica; elementos expuestos; productos peligrosos.

RESUMO: A redução de riscos a desastres está ganhando relevância no campo das ciências ambientais, sendo frequentemente abordada em diagnósticos territoriais. Neste sentido, o presente trabalho tem como objetivo analisar e avaliar os níveis de ameaça tecnológica com relação ao armazenamento de produtos perigosos na cidade de Paranaguá. A metodologia desenvolvida tem como base teórica a legislação espanhola Reglamento de Actividades Molestas, Insalubres, Nocivas y Peligrosas de 1961, bem como é complementada com as pro- 
postas da Organização das Nações Unidas (ONU) e da Agência Nacional de Transportes Terrestres (ANTT) do Brasil. A análise foi realizada, com o auxílio do software ArcGIS 10.1, considerando a distância como fator de exposição. A partir da aplicação desta metodologia, pode se concluir que um total de $84,75 \mathrm{~km}^{2}$ estão sob ameaças tecnológicas e mais de 124.000 pessoas seriam afetadas no caso de acontecer um evento.

Palavras-chave: ameaça tecnológica; elementos expostos; produtos perigosos.

ABSTRACT: The reduction of disaster risks is gaining relevance in the environmental sciences, resulting in very relevant territorial diagnoses. Having that in mind, the goal of the present work is to analyze and evaluate the levels of technological threats arising from the storage of dangerous products in the city of Paranaguá. The developed methodology has been theoretically based in the Spanish legislation "'Reglamento de Actividades Molestas, Insalubres, Nocivas y Peligrosas, 1961" (Regulation of Irritating, Unhealthy, Noxious and Dangerous Activities, 1961), as well as complemented with a proposal from the Organization of the United Nations (UN) and from the National Agency of Land Transports of Brazil (ANTT). The analysis was performed with the help of the ArcGIS 10.1 software, considering distance as an exposure factor. From the application of this methodology, it can be inferred that $84.75 \mathrm{~km}^{2}$ are under technological threat, and more than 124,000 people would be affected in case an event takes place.

Keywords: technological threats; exposed elements; dangerous products.

\section{Introducción}

Las medianas y grandes ciudades, principalmente de los países en desarrollo, se han convertido, en las últimas décadas, en los escenarios perfectos para la materialización de desastres. Los diferentes usos del suelo, que a veces no son compatibles entre sí en un mismo territorio, la gran concentración de población y la falta de políticas de planificación integral, son algunos de los elementos claves para entender la compleja relación entre urbanización y riesgo de desastre. Desde el momento en que se considera que los procesos de planificación deben ser integrales y tener sus bases en el desarrollo sustentable, se puede pensar en una gestión estratégica del territorio. En este sentido, la reducción del riesgo de desastres aparece como un eje central en los procesos de planificación para alcanzar un desarrollo seguro, equilibrado y con duración en el tiempo (EIRD, 2004).

\begin{abstract}
"Hoy por hoy es fundamental empezar a reconocer que en todas nuestras ciudades existen flujos muy importantes de materiales que, sin dejar de reconocer su peligrosidad, son a su vez insumos vitales de algunos procesos económicos que en esa ciudad se gestan, de allí la necesidad de desarrollar esfuerzos permanentes destinados a conocer cuáles son los niveles de riesgo tecnológico propios de cada espacio urbano y que mecanismos deben ser implementados a fin de propiciar la reducción de los mismos" (Linayo, 2009, p. 178).
\end{abstract}

Es en este contexto que se fundamenta el presente trabajo, en el cual se estudia a la ciudad portuaria de Paranaguá y sus niveles de riesgo tecnológico. Esta localidad se encuentra ubicada en el litoral brasilero, en las coordenadas $25^{\circ} 31$ ' 12 " S y $48^{\circ} 30^{\prime} 33^{\prime}$ 'W, (Figura 1) y presentaba para el 2010 una población de 140.469 habitantes, lo que la colocaba como la décima más poblada del estado de Paraná, según el Instituto Brasilero de Geografía y Estadística (IBGE, 2010). La ciudad fue fundada en el año 1792 en las márgenes del río Itiberê (primer 
puerto) y a partir de allí comenzó su expansión. Durante la década de los ' 80 , la localidad creció en torno a la ruta estadual 277 , hasta que las áreas para urbanización se tornaron escasas y los asentamientos comenzaron a realizarse en áreas no aptas para habitar (Soares, 2009). De este modo fueron pobladas algunas zonas en torno al nuevo puerto, Don Pedro II, generando la convivencia de la población con los parques de almacenaje de productos.

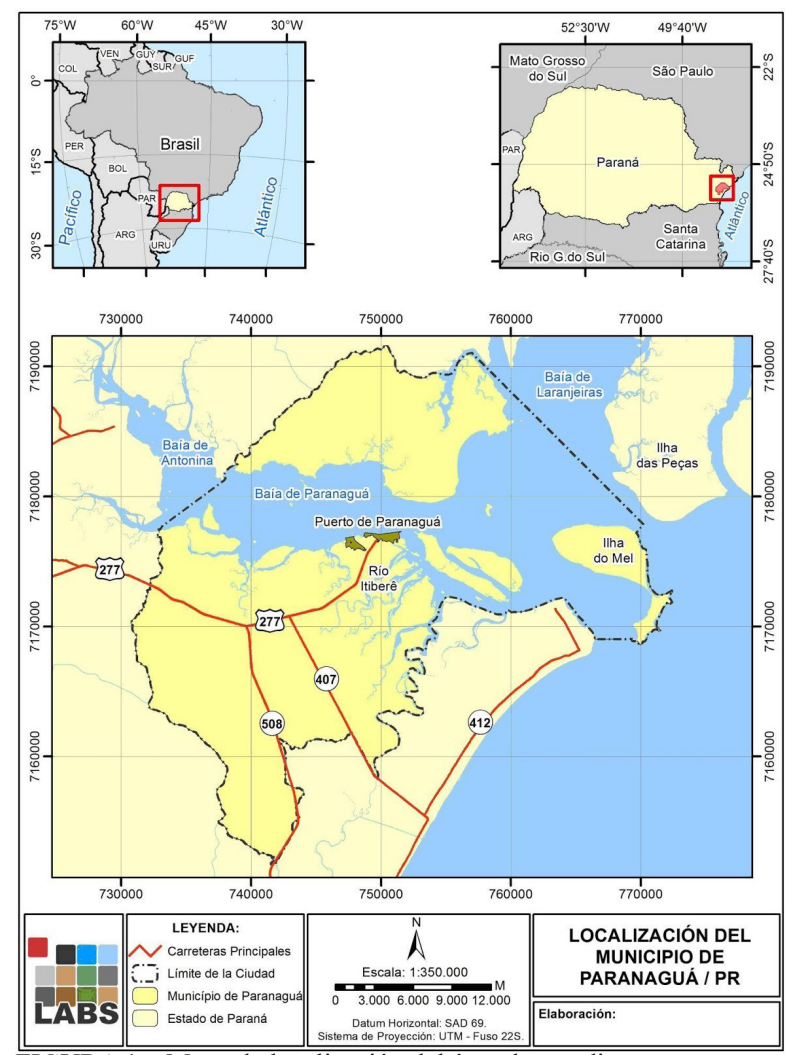

FIGURA 1 - Mapa de localización del área de estudio.

FUENTE: elaboración propia.

Inicialmente el puerto de Paranaguá se localizaba en aguas menos profundas lo que imposibilitaba que barcos de gran porte consiguieran anclar.
Por este motivo, en 1935 se produjo la mudanza del puerto para un lugar de aguas más profundas, permitiendo el flujo de barcos mayores y consecuentemente potencializando las actividades urbanas de Paranaguá. Esta posibilidad de recibir barcos más grandes y el incremento de la producción de café en el Estado de Paraná, posibilitaron que en la década del ' 50 el puerto de Paranaguá recibiera el título del mayor exportador de café del mundo (ACE, 2012).

Actualmente, Paranaguá cuenta con el puerto más importante de América Latina en relación a la carga de granos, y con el segundo puerto más significativo de Brasil por su destacada infraestructura y flujo comercial (PDZPO, 2012). En el año 2014 este puerto movilizó 45,6 millones de toneladas de productos, según la Associação Nacional de Transportes Aquaviários (ANTAq, 2015), lo que representó el 4,3\% de la movilización en puertos públicos brasileros y el $29,1 \%$ de las cargas movilizadas en la región sur del país.

Muchos de estos productos que pasan por el puerto son almacenados en la zona portuaria en grandes tanques y almacenes. Las principales cargas comercializadas son: granel sólido (soja, maíz) containers, granel líquido (derivados del petróleo, alcohol, aceite de soja), fertilizantes y automóviles. La mayoría de ellas se encuentran almacenadas en la zona portuaria, que se sitúa en el área urbana del municipio. Varios de estos productos tienen elevados niveles de inflamabilidad y el almacenaje en grandes cantidades representa una amenaza para los elementos expuestos. Actualmente, existen más de cuarenta empresas operando en este puerto y muchas de ellas (veinticinco) comercializan productos inflamables.

La concentración de tanques que almacenan productos peligrosos (154 tanques con una capa- 
cidad de $540.781 \mathrm{~m}^{3}$, según PDZPO, 2012) la elevada densidad de población urbana (5.069,04 hab/ $\mathrm{km}^{2}$, según el IBGE, 2010), y el alto porcentaje de ocupaciones irregulares ( $26 \%$ da área urbana, según el PDM, 2006) ponen en evidencia que el análisis de riesgo de desastre debe ser un tema abordado desde la planificación local.

Sumado a estas características, cabe destacar, que la ciudad de Paranaguá está rodeada por más de veinte unidades de conservación con diferentes grados de restricción, en cuanto al uso de los recursos, y con objetivos de preservación de ecosistemas frágiles o endémicos. La mayoría de estas unidades pertenecen al Mosaico Lagamar representado por una extensa área del litoral paranaense y del litoral paulista destinada a la conservación. Por lo tanto, la evaluación del riesgo en conjunto con la planificación territorial no posee solo motivos sociales para ser desarrollada, sino que tiene varios y verdaderos motivos ambientales que exigen su implementación con urgencia.

En el presente trabajo será profundizado el análisis en torno a los niveles de amenaza tecnológica (Poffo et al., 2005; Boulaich et al., 2007; Cardoso Rodrigues, 2008; Linayo, 2009 y Torrisi et al., 2015) que existen en esta localidad portuaria y de qué manera están territorializados. Para conseguir este objetivo, es importante definir al riesgo tecnológico y entender sus componentes. Según Bosque Sendra et al. (2004), el riesgo tecnológico hace referencia a la probabilidad de sufrir daños o pérdidas económicas, ambientales y humanas como consecuencia del funcionamiento deficiente o accidente de una tecnología aplicada en una actividad humana. . En las investigaciones sobre los riesgos, comúnmente se considera que la magnitud del riesgo es una consecuencia de la interacción de de tres factores: 1) la localización, volumen, probabilidad de ocurrencia de accidentes y características de peligrosidad de la actividad que se considera fuente de riesgo, 2) las dimensiones y características del área expuesta a un posible accidente y 3) el grado de la vulnerabilidad de los posibles receptores del daño. En este artículo se pretende presentar resultados en torno a los dos primeros aspectos, estrechamente relacionados a los niveles de amenaza.

A partir de estas nociones teóricas fue construida una metodología para determinar niveles de amenaza tecnológica. Para esto se tomará como base la propuesta de Bosque Sendra y su equipo, fundamentada en una normativa española donde se hace referencia al desarrollo de actividades peligrosas lo que permite identificar áreas amenazadas. Teniendo en cuenta que la realidad española es diferente a la brasilera pero que, en este caso, las densidades urbanas son similares, se aplicará la metodología de la ciudad europea. Para complementar esto, fueron incorporadas las recomendaciones de la Organización de las Naciones Unidas en el manual titulado Recomendaciones relativas al transporte de mercancías peligrosas. Reglamentación Modelo (ONU, 2013), donde se elaboró una propuesta en la que identifica los productos peligrosos que son transportados por vía terrestre. A partir de esto, se evalúan diversas características del producto y la Agencia Nacional de Transporte Terrestre brasilera (ANTT, 2004) otorga un número del peligro donde se reflejan los posibles riesgos asociados. En la clasificación propuesta por la ANTT, se evalúan diversas características para otorgar un número único a cada producto con un significado específico, lo que permite hacer una jerarquización de los mismos, según su nivel de peligrosidad.

Este trabajo, que profundiza en la evaluación 
de amenazas, pretende ser la base para próximos estudios en lo que respecta a la definición de niveles de vulnerabilidad, de la población que vive en la proximidad de estas empresas, y a la evaluación de niveles de riesgo tecnológico en la zona portuaria de Paranaguá. La importancia de un análisis como el que aquí se presenta, radica en los aportes que estos resultados pueden significar para los procesos de planificación territorial. Además de este análisis, que permitirá tener nociones concretas de áreas posiblemente afectadas ante un evento, se presentan sintéticamente algunos casos ya ocurridos en la ciudad de Paranaguá, buscando dimensionar el riesgo allí presente. Entre el año 1992 y el 2009 se registraron siete eventos de diferente magnitud y con diversos impactos vinculados con amenazas tecnológicas.

\subsection{Eventos acontecidos en la región}

Entre los años 1992 y 2009 en la localidad de Paranaguá, específicamente en su zona portuaria y retroportúaria, ocurrieron siete eventos vinculados a amenazas peligrosas. Estos acontecimientos fueron principalmente explosiones, seguidas de derrames de productos e incendios. Seguramente, otros eventos deben haber tenido lugar en años anteriores, pero no se cuenta con el registro documentado de ellos. A continuación se presenta una breve descripción de cada evento y algunas de sus consecuencias.

- En enero de 1992 ocurrió la explosión de un silo vertical produciendo la muerte de dos trabajadores y provocando heridas en otros cinco. La probable causa, señalada en la época, habría sido la combustión de polvo de cebada que estaba almacenada en el silo al momento de una limpieza, que acontecía en el décimo piso de la estructura, que tenía 13 pisos y 55 metros de altura (Rangel-Junior, 2007).

- En octubre del 2000, cinco mil litros de aceite diesel se filtraron de un oleoducto de la Transpetro, perteneciente a la empresa Petrobras, localizada en el puerto (Bruns Neto, 2004 apud Tonetti, 2011).

- En noviembre de 2001, ocurrió una explosión en el depósito de almacenamiento de granos del Corredor de Exportación del Puerto de Paranaguá. Algunas fallas en el proceso de descarga pueden haber sido la causa del accidente al provocar la formación de una atmósfera explosiva, dejando algunas personas heridas. Los técnicos del puerto afirmaron que el desastre puede haberse causado por una limpieza deficiente de las cintas que transportaban las cinco mil toneladas de maíz estocadas en el lugar. La explosión tuvo una magnitud tal, que pedazos de zinc, que formaban parte del techo, fueron lanzados hasta mil metros de distancia, y estructuras de cemento, con más de trescientos kilos, también fueron encontradas lejos del lugar (Rangel-Junior, 2007).

- En noviembre del 2004, un incendio destruyó parte de un almacén de $2.800 \mathrm{~m}^{2}$, que contenía una carga de fardos de algodón (Bruns Neto, 2004 apud Tonetti, 2011).

- En noviembre del 2004, explotó el barco Vicuña, de bandera chilena, durante la operación 
de descarga de metanol. En el momento del accidente centenas de personas estaban en la plaza situada en frente al Santuario Estadual de Nossa Senhora do Rocio, cerca de la terminal de productos inflamables del Puerto de Paranaguá. Como consecuencia, cuatro tripulantes murieron y el barco se quebró y se incendió por completo, además de causar el derrame de combustible que afectó varios ecosistemas y comunidades pesqueras (Soares, 2009).

- En agosto del 2007, ocurrió una explosión en las instalaciones de una refinería de sal, instalada en la Avenida Bento Rocha, a 600 metros del Puerto de Paranaguá. Cerca de 50 familias, del barrio Guadalupe, tuvieron que dejar las casas y cuatro viviendas fueron destruidas (Kohlbach, 2007 apud Tonetti, 2011).

- En julio del 2009, varias familias fueron evacuadas de sus casas, debido a una fuga de etanol que ocurrió durante una operación de descarga del producto que llegó al Terminal Público de alcohol de Paranaguá en vagones de la empresa ALL (Cesca, 2009 apud Tonetti, 2011).

Sumado a estos eventos documentados en Paranaguá, en el mes de abril del 2015 ocurrió el peor incendio en la historia del Estado de San Pablo en la empresa Ultracargo. El de tipo de productos almacenados, la forma de almacenamiento de estos productos y los modos de movilización, transporte y comercialización de esta empresa en Santos, son similares a los que utilizan algunas empresas de Paranaguá. Por este motivo, es que se exponen algunas consecuencias, considerando que son datos ricos ricospara conseguir planificar y prevenir un hecho similar.

El incendio en Santos involucró cinco tanques de gasolina y uno de etanol con 6 millones de litros cada uno, debido a la alta inflamabilidad de estos productos, el incendio estuvo fuera de control en varios momentos y solo fue declarado extinto después de nueve días de intentos por combatirlo (Globo, 2015). Teniendo en cuenta las características de este evento y sus consecuencias, aún desconocidas en su totalidad, se considera relevante el desarrollo de estudios que puedan evaluar los niveles de amenaza tecnológica que representa la presencia de empresas que manipulan materiales peligrosos y sus implicancias en la planificación del desarrollo local. Las consecuencias que hoy sufre Santos pueden ser las que en un futuro sufra Paranaguá sino toma medidas de reducción de riesgo, y sobre todo si no las incorpora en sus procesos de planificación local.

\section{Materiales y métodos}

El marco metodológico implementado tiene como base el Reglamento de Actividades Molestas, Insalubres, Nocivas y Peligrosas (RAMINP), aprobado en el decreto 2414/1961, de 30 de noviembre, en España. Dicho reglamento tiene como objetivo "evitar que las instalaciones, establecimientos, actividades, industrias o almacenes, sean oficiales o particulares, públicos o privados, a todos los cuales se aplica indistintamente en el mismo la denominación de 'actividades', produzcan incomodidades, alteren las condiciones normales de salubridad e higiene del medio ambiente y ocasionen daños a las riquezas pública o privada o impliquen riesgos graves para las personas o los bienes" (RAMINP, 1961, p. 1). A los efectos del presente trabajo se ha 
tomado la definición que el mismo RAMINP (1961) hace en relación a lo que se considera como una actividad peligrosa: "se consideran peligrosas las que tengan por objeto fabricar, manipular, expender o almacenar productos susceptibles de originar riesgos graves por explosiones, combustiones, radiaciones u otros de análoga importancia para las personas o los bienes.

Si bien el reglamento es bastante antiguo y pertenece a un país europeo, es uno de los pocos donde se explicitan distancias concretas (2000 metros en general) a ser tenidas en cuenta entre los núcleos de población y el desarrollo de la industria peligrosa, por lo tanto, se ha tomado como referencia. Sumado a esto, las densidades urbanas de Madrid y de Paranaguá para el año 2010 eran similares, $5.421,38 \mathrm{hab} / \mathrm{km}^{2}$ (Ayuntamiento de Madrid, 2010) y $5.069,04 \mathrm{hab} / \mathrm{km}^{2}$ (IBGE, 2010), respectivamente, lo que posibilita realizar una aproximación en el método. Se debe señalar que la distancia de 2000 metros ha sido definida de modo general y es necesario que en cada estudio se realice una lectura crítica del RAMINP y una adaptación según el tipo de producto almacenado o industrializado, y el volumen del mismo.

Se han analizado más de cuarenta empresas radicadas en el puerto de Paranaguá y solo veinticinco de ellas (cuyas estructuras están distribuidas en veintinueve terrenos, ya que algunas poseen más de una planta industrial) se han considerado para la determinación de niveles de amenaza tecnológica. El criterio para la selección fue tomar como base un cuestionario que cada establecimiento debió responder en el año 2012 a la Administración de los Puertos de Paranaguá y Antonina (APPA), con el fin de realizar mapas de riesgo locales. Entre las preguntas que se realizaron algunas fueron identi- ficadas como claves para este trabajo:

1) ¿Existen productos peligrosos siendo producidos, transportados, almacenados y/o manipulados en la empresa?

2) ¿Cuáles son los productos (número de la ONU) y cuál es su cantidad?

Ante la respuesta positiva a la primera pregunta automáticamente se considera a la empresa como foco de amenaza tecnológica. Luego de identificar los establecimientos, según la sustancia almacenada (número ONU Tabla 1) y el número de peligrosidad establecido por la ANTT (Tabla 2), fueron confeccionados diferentes buffers que representarán el área posiblemente afectada frente a un evento potencial.

Cabe aclarar, que por un lado, la ONU otorga a cada sustancia un número de cuatro cifras que la identifica, y por otro lado, cada sustancia posee su número del peligro compuesto por 2 ó 3 cifras explicadas, cada una de ellas, en el Tabla 2.

TABLA 1 - Categoría numérica de los productos según la ONU.

\begin{tabular}{ll}
\hline \multicolumn{1}{c}{ Producto } & Número ONU \\
\hline Acetileno disuelto & 1001 \\
Amoníaco anhidro & 1005 \\
Hidrógeno comprimido & 1049 \\
Bromuro de metilo & 1062 \\
Nitrógeno comprimido & 1066 \\
Gases del petróleo licuado & 1075 \\
Dimetilamina, disoluciones acuosas & 1160 \\
Alcohol etílico, soluciones acuosas & 1170 \\
Etilmetilcetona & 1193 \\
Combustible para motores diesel & 1202 \\
Gasolina & 1203
\end{tabular}


Isopropilamina

1221

Metanol

1230

Pinturas o materias para pinturas

1263

Destilados del petróleo

1268

Metilato sódico en disolución alcohólica

1289

Nitrato potásico

1486

Ácido clorhídrico en disolución

Ácido fosfórico

1789

1805

Hidróxido sódico

1824

Ácido sulfúrico con más del 51\% de ácido

1830

Combustible para motores de turbinas de aviación

Líquido inflamable

1993

Abonos a base de nitrato amónico tipo A1

Nitrato amónico líquido, (en disolución

caliente concentrada)

Plaguicida a base de carbamato, sólido, tóxico

Plaguicida a base de organofosforado sólido, tóxico

Fosfato ácido de amilo

Plaguicida líquido, tóxico

Plaguicida organofosforado líquido, tóxico, inflamable

Materia sólida potencialmente peligrosa para el medio ambiente

Materia líquida potencialmente peligrosa para el medio ambiente

Bromatos inorgánicos en disolución acuosa

Líquido orgánico, corrosivo, básico

Hidrocarburos líquidos

Plaguicida piretroideo sólido, tóxico

Plaguicida piretroideo líquido, tóxico
TABLA 2 - Número del peligro y significado, según la ANTT (2004).

\begin{tabular}{|c|c|}
\hline Cifra de Peligro & Significado \\
\hline 2 & $\begin{array}{c}\text { Emanación de gas resultante de presión o de } \\
\text { una reacción química }\end{array}$ \\
\hline 3 & Líquidos (vapores) y gases inflamables \\
\hline 4 & Sólidos inflamables \\
\hline 5 & Materia comburente (favorece incendios) \\
\hline 6 & Toxicidad \\
\hline 7 & Radiactividad \\
\hline 8 & Corrosividad \\
\hline 9 & Peligro de reacción violenta espontánea \\
\hline
\end{tabular}

Cuando el peligro de una materia puede ser identificado suficientemente con una sola cifra, esta se completará con un cero en segunda posición. Las cifras repetidas indican una intensificación del peligro.

FUENTE: Resolución n 420, de 12/02/2004 (ANTT, 2004).

Con fines prácticos fueron clasificadas las empresas según los números del peligro de las sustancias que almacenan y se las clasificará de la siguiente manera:

- Las que poseen productos con cifras del peligro 2, 3 o 4 tendrán una amenaza MEDIA y un buffer de 1500 metros;

- Las que poseen productos con cifras del peligro entre 5 o 6 tendrán una amenaza ALTA y un buffer de 2000 metros;

- Y por último, las que poseen cifras del peligro 7, 8 o 9 tendrán una amenaza MUY ALTA y un buffer de 2500 metros.

FUENTE: ONU (2013). 
Se ha decidido que el buffer máximo exceda 500 metros al propuesto por la legislación española, debido a que en esta área de estudio existe una zona portuaria y de almacenaje de productos, por lo que la concentración de elementos peligrosos es mayor que en una urbanización común.

Dicha metodología fue dividida en dos grandes pasos y se desarrollará utilizando el SIG ArcGIS 10.1. En un primer momento se trabajó con la definición del área expuesta a la amenaza tecnológica (definida por buffers), y para esto fueron consideradas las formas de los focos de riesgo y el alcance espacial (Bosque Sendra et al., 2004) que podrían tener los efectos peligrosos (basados en RAMINP, con adaptaciones según el número de la ONU y el de peligrosidad que otorga la ANTT a cada producto).

Una vez obtenido este resultado, se procedió al segundo momento, donde fueron caracterizadas cada una de esas áreas expuestas. Para esto se tomaron como base los buffers confeccionados anteriormente y utilizando la variable visual intensidad y el recurso de álgebra de mapas (Barbosa et al., 1998, p. 487), se construyó una gradación de tonos para indicar que la exposición es directamente proporcional a la cercanía del foco peligroso. El siguiente paso fue evaluar la probabilidad espacial de sufrir un desastre tecnológico, para esto, se parte de la hipótesis de que cuantos más focos de peligro afecten un área, mayor será su exposición a un desastre, por lo tanto la superposición de buffers aumentará el nivel de amenaza (Bosque Sendra et al., 2004).

Para representar los datos de probabilidad espacial, se trabajó con una escala entre 0 y 1 (usualmente utilizada para probabilidad) y fue implementada una distribución de esos datos por intervalos naturales (Jenks, según el ArcGIS). Por último, con base en los datos del censo del 2010, se realizó un análisis de la cantidad de población afectada para cada nivel de intensidad y probabilidad frente a un posible evento.

Cabe hacer algunas aclaraciones para aplicar esta metodología y obtener resultados acertados. En primer lugar, el medio geográfico fue entendido como uniforme, esto a fines prácticos y para implementar una metodología rápida y eficiente que sirvió como guía para identificar áreas amenazadas. Ciertamente, el medio estudiado no es uniforme, pero en este trabajo no se hicieron tratamientos diferentes, ni un análisis de pendientes, dirección de los vientos, etc. Esta metodología arrojó resultados generales que podrán ser profundizados por barrio o por empresa incorporando algunas variables, como las mencionadas anteriormente.

Un segundo aspecto a considerar es que se ha tomado como base la propuesta de la ONU, de numerar las sustancias peligrosas, y se la ha complementado con lo establecido por la ANTT, pero ambas metodologías se han confeccionado para analizar productos a ser transportados. En este caso, los productos están almacenados en grandes tanques en la zona portuaria, por lo que la numeración sirvió como referencia general y puede ser complementada para obtener datos más precisos.

El tercer y último aspecto a tener en cuenta, es que en este trabajo se han integrado dos fuentes de información y dos propuestas metodológicas (la basada en el RAMINP y la propuesta de la ONU que da la base teórica a lo que determina la ANTT) de cómo tratar a las amenazas tecnológicas. Esto puede requerir ajustes a futuro y adaptaciones para la obtención de resultados cada vez más aproximados a la realidad.

Por último, para concluir el trabajo, se realizó una breve descripción de eventos, vinculados a ame- 
TABLA 3 - Número ONU y número del peligro por empresa, Paranaguá, 2014.

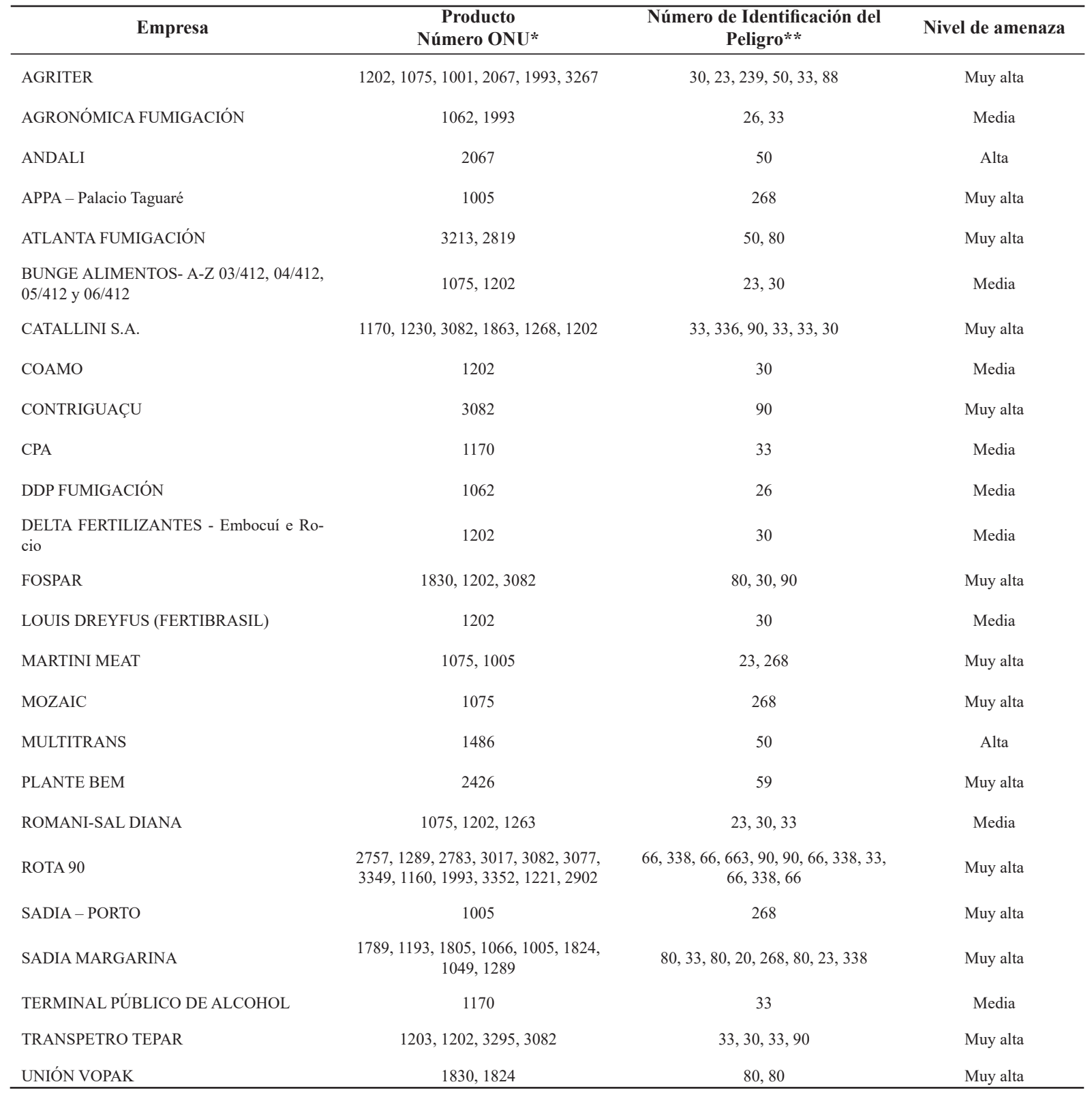

*Ver Tabla 1.

**Números de Identificación del Peligro ordenados respectivamente en relación a los números de la ANTT (Tabla 2).

FUENTE: elaboración propia en base a datos de la APPA, la ANTT y de www.proteccioncivil.org 
nazas tecnológicas, ya ocurridos en la localidad de Paranaguá entre los años 1992 y 2009 y una pequeña referencia a la explosión ocurrida en Santos/SP en abril del 2015.

\section{Discusión y resultados}

A partir del RAMINP, del número ONU y de los números de peligrosidad propuestos por la ANTT para cada sustancia, se analizaron los distintos productos almacenados por cada empresa en Paranaguá (Tabla 3). Cada empresa, en general, almacena más de un producto, por lo que se tomaron en cuenta todos, considerando que estos elementos son almacenados en tanques y luego exportados y que por más mínimo que sea su volumen, será representativo.

Con esta clasificación como referencia se confeccionaron diferentes buffers atendiendo a los diversos niveles de amenaza:

- Buffer de 2500 metros para las 14 empresas con productos con amenaza MUY ALTA;

- Buffer de 2000 metros para las 2 empresas con productos con amenaza ALTA;

- Buffer de 1500 metros para las 9 empresas con productos con amenaza MEDIA.

A partir de estos datos, se puede realizar una descripción para cada caso específico, por ejemplo, la empresa Agriter almacena, entre otros productos, acetileno disuelto (número ONU 1001) que posee un número del peligro 239 (lo que significa que puede producirse una emanación de gas resultante de presión o de una reacción química, que este es un gas inflamable y que puede desencadenar una reacción violenta espontánea), por lo tanto su nivel de amenaza tecnológica es muy alto y el buffer que se realizó para esa empresa fue de 2500 metros.

Con estos datos obtenidos para cada empresa se lograron definir los niveles de amenaza y mapear cada uno de ellos (Figura 2). En el siguiente mapa se puede ver que el área afectada ocupa 95,7\% del área urbana (según la mancha urbana del 2010) y poco menos de un décimo $(9,75 \%)$ del municipio de Paranaguá $\left(826,67 \mathrm{~km}^{2}\right)$. Además, se encuentran bajo amenaza una importante porción marina (22,35 $\mathrm{km}^{2}$ ) y algunas porciones insulares, entre las que se destaca la Ilha dos Valadares que posee aproximadamente 13.798 habitantes. La mancha urbana, como se señaló antes, está casi por completo bajo el área de amenaza tecnológica, lo que demuestra la urgencia de una planificación integral que contemple medidas preventivas, correctivas y prospectivas.

En el siguiente mapa (Figura 3) se representó la intensidad de la exposición a las amenazas tecnológicas en Paranaguá. A partir de este mapa se pueden identificar las áreas que serían más afectadas o que estarían más expuestas ante la posible ocurencia de un evento. Lógicamente estas áreas coinciden con los predios más cercanos a las empresas, los barrios en los que estas están instaladas son los primeros focos para empezar con trabajos preventivos y de sensibilización. El 63,36\% de la población expuesta está bajo niveles de amenaza media, alta o muy alta, dentro de ese porcentaje se destaca que solo 14.212 personas están bajo amenaza muy alta. Si bien el valor absoluto no es tan elevado, la concentración de población sí lo es, lo que implica que hay una densidad de 1.685,76 hab. $/ \mathrm{km}^{2}$ expuestos a amenazas muy altas. Frente 
a algún acontecimiento nocivo la densidad de población elevada no contribuye a facilitar las tareas de evacuación y de atención de la emergencia. La densidad poblacional en áreas con niveles de amenaza media o mayor a esta es de 2.014,69 hab. $/ \mathrm{km}^{2}$, lo que resulta un valor aún más alarmante.

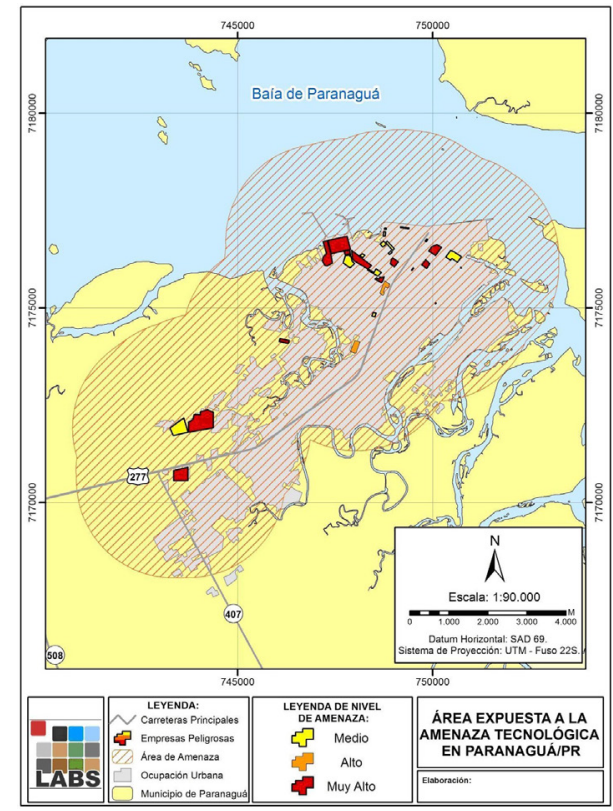

FIGURA 2 - Mapa de localización del área de estudio.

FUENTE: elaboración propia.

La zona portuaria es sin duda la principal y mayor área amenazada y de conflicto. Debido a la gran concentración de empresas peligrosas, la importancia que tiene a nivel económico y la alta densidad de personal, el puerto se vuelve un sitio que debe ser analizado con un enfoque de reducción de riesgo de desastres de modo casi urgente. La zona de los muelles es una de las más críticas lo que permite inferir que la zona marítima (fauna, calidad de las aguas, etc.) también estaría altamente comprometida en caso de algún accidente.

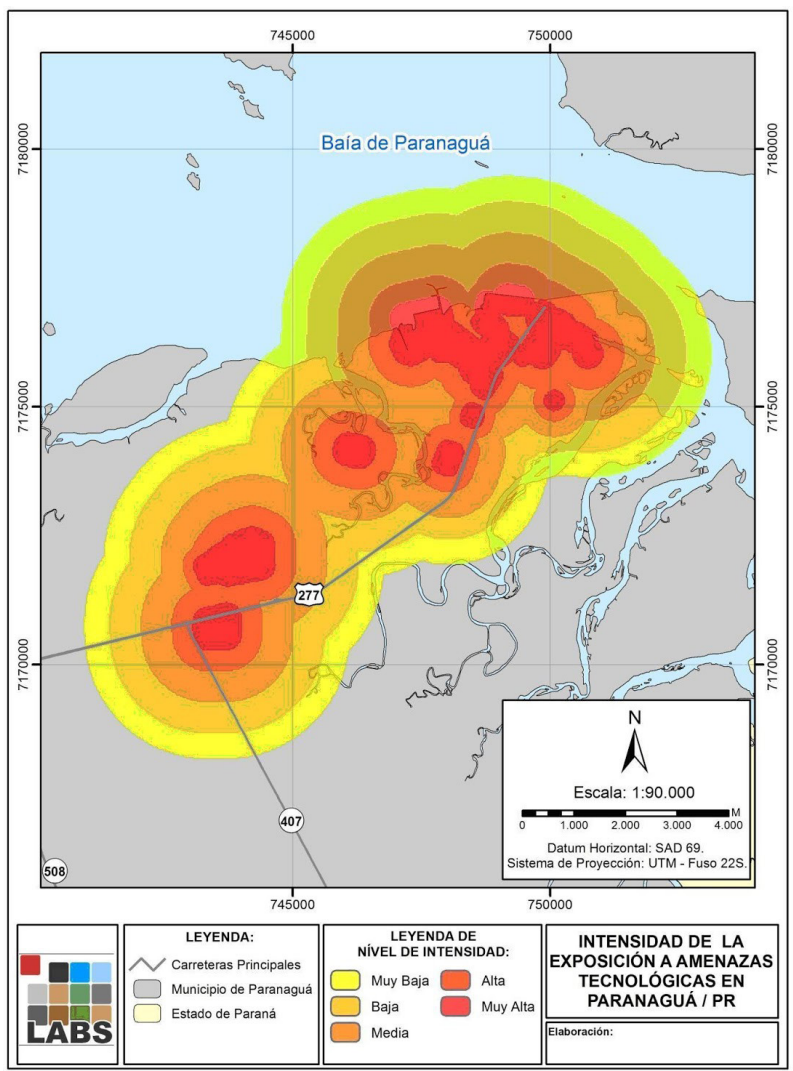

FIGURA 3 - Mapa de intensidad de la exposición a amenazas tecnológicas.

FUENTE: elaboración propia en base al Tabla 3.

Existen también otros focos de amenaza muy alta más aislados y distantes del puerto, lo que posiblemente coloca bajo amenaza a otro tipo de elementos e infraestructura como hospitales, escuelas, e iglesias, entre otros, donde puede haber una gran concentración de población de modo constante. Estos establecimientos, por un lado, pueden concentrar un gran número de habitantes al momento de ocurrir un desastre, por lo que es esencial identificarlos como puntos críticos. Pero al mismo tiempo, si cuentan con la preparación nece- 
saria, pueden ser puntos claves en la ciudad para atender la emergencia y colaborar desastre, por lo que es esencial identificarlos como puntos críticos. Pero al mismo tiempo, si cuentan con la preparación necesaria, pueden ser puntos claves en la ciudad para atender la emergencia y colaborar con el asilo grado de amenaza. Para definir estas estrategias, será fundamental el análisis de vulnerabilidad que complementará al de amenazas y mostrará estas especificidades en cada región.

Cabe destacar que el municipio de Paranaguá cuenta con grandes áreas de sierra, de mar y de

TABLA 4 - Valores de superficie y de población en cada tipo de situación de exposición, en la ciudad de Paranaguá (Cifras absolutas, 2010).

\begin{tabular}{|c|c|c|c|}
\hline Zonas & Área $\left(\mathbf{K m}^{2}\right)$ & Población Total & $\begin{array}{c}\text { Densidad } \\
\text { Poblacional }\left(\mathbf{h a b} . / \mathbf{k m}^{2}\right)\end{array}$ \\
\hline No Expuestas & 741,93 & 15.724 & 21,19 \\
\hline Expuestas & 84,75 & 124.745 & $1.471,91$ \\
\hline \multicolumn{4}{|c|}{ Intensidad espacial } \\
\hline Nivel de intensidad & Área $\left(\mathrm{Km}^{2}\right)$ & Población Total & $\begin{array}{c}\text { Densidad } \\
\text { Poblacional }\left(\mathrm{hab} . / \mathrm{km}^{2}\right)\end{array}$ \\
\hline$>0 \leq 0,25$ & 26,32 & 16.040 & 609,42 \\
\hline$>0,25 \leq 0,50$ & 19,19 & 29.664 & $1.545,80$ \\
\hline$>0,50 \leq 0,75$ & 19,59 & 37.218 & $1.899,84$ \\
\hline$>0,75 \leq 0,90$ & 11,22 & 27.612 & $2.460,96$ \\
\hline$>0,90 \leq 1$ & 8,43 & 14.211 & $1.685,76$ \\
\hline \multicolumn{4}{|c|}{ Probabilidad espacial } \\
\hline Nivel de probabilidad & Area $\left(\mathrm{Km}^{2}\right)$ & Población Total & $\begin{array}{c}\text { Densidad } \\
\text { Poblacional }\left(\mathrm{hab} . / \mathrm{km}^{2}\right)\end{array}$ \\
\hline$>0 \leq 0,087$ & 54,53 & 64.064 & $1.174,83$ \\
\hline$>0,087 \leq 0,223$ & 16,74 & 20.667 & $1.234,58$ \\
\hline$>0,223 \leq 0,419$ & 6,65 & 22.011 & $3.309,92$ \\
\hline$>0,419 \leq 0,665$ & 4,03 & 12.689 & $3.148,63$ \\
\hline$>0,665 \leq 1$ & 2,80 & 5.314 & $1.897,85$ \\
\hline
\end{tabular}

FUENTE: elaboración propia en base a datos del IBGE (2010).

y la atención de los evacuados que lo requieran. Esto permite visualizar que al momento de planifi car se tendrán que tener diferentes estrategias para diversas zonas, por más que presenten el mismo reservas naturales, lo que explica que más del $88 \%$ de la población viva en un área de menos de 85 $\mathrm{km}^{2}$ (Tabla 4).

Por este motivo es que la densidad urbana de 
Paranaguá alcanza valores tan elevados, lo que se convierte en un factor clave para entender la configuración de las amenazas en el territorio y poder identificar la distribución de los elementos expuestos.

La Figura 4 representa el mapa de probabilidad espacial de que un área sea afectada por algún evento de origen tecnológico. Aquí se ha considerado que cuantos más focos de amenaza afecten a una zona, más elevada será su probabilidad y su grado de exposición. La zona portuaria es la región potencialmente más comprometida debido a la gran concentración de establecimientos (más de diez empresas) con amenaza tecnológica en una porción pequeña de territorio. Unas 18.003 personas están viviendo en un área (de $6,83 \mathrm{~km}^{2}$ ) donde las probabilidades de ser afectadas por una amenaza tecnológica son altas (entre 0,4 y 1 ). La zona con mayor probabilidad (entre 0,6 y 1) de sufrir las consecuencias de algún fenómeno tecnológico nocivo, posee una densidad poblacional muy elevada de $1.897,14 \mathrm{hab} / \mathrm{km}^{2}$. Sumado a eso, la ocupación de varias de estas zonas fue realizada de modo espontáneo y se han tomado los terrenos para la construcción de casas, siendo muy precaria la calidad de los materiales de construcción utilizados (PDM, 2006). Estos resultados obtenidos son claves para la planificación integral de esta ciudad, ya que Paranaguá tiene como gran motor económico al puerto Don Pedro II, que es principal generador de empleo local (PDZPO, 2012) y es allí mismo donde se encuentra la mayor probabilidad de que ocurra un evento. El resto del área afectada $\left(77,92 \mathrm{~km}^{2}\right)$, en general, posee resultados de probabilidad muy bajos, por lo que se puede inferir que la mayoría de los lugares están influenciados por uno o por muy pocos establecimientos peligrosos.

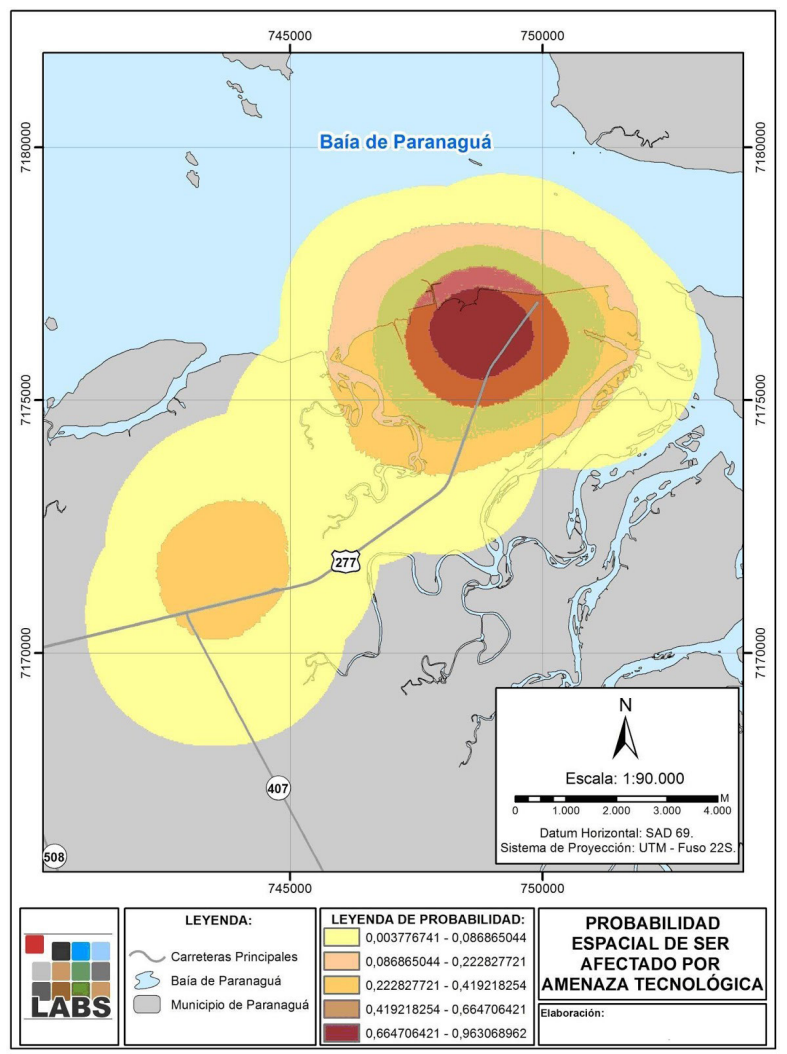

FIGURA 4 - Mapa de probabilidad espacial de ser afectado por un fenómeno tecnológico.

FUENTE: elaboración propia.

Más allá de estos resultados, que manifiestan la intensidad y probabilidad de afectación de un evento hipotético en la ciudad de Paranaguá, existen varios eventos que ya han ocurrido y que dan la pauta de lo expuesta que está la comunidad al vivir en un área con amenaza tecnológica.

\section{Conclusiones}

A partir del análisis desarrollado se pueden 
hacer algunas reflexiones finales, principalmente en torno a algunos resultados y a cuestiones metodológicas. El puerto de Paranaguá es el más importante de América Latina en lo que respecta a cargas a granel y es el gran motor económico de la ciudad, pero como contra cara a esto, es un área altamente expuesta a amenazas tecnológicas. El 95,7\% del área urbanizada se encuentra bajo amenaza, en mayor o menor medida, lo que genera la exposición de una alta cantidad de infraestructura y de más de 124.000 personas que viven allí. Sumado a esto, en la zona portuaria se concentran los valores más altos de probabilidad de que ocurra algún evento desafortunado. Estas probabilidades y su significado son fundamentales para pensar en la planificación del desarrollo de esta ciudad portuaria que cuenta con escenarios altamente complejos.

En dichos escenarios conviven diversos usos de suelo que a veces no son compatibles, como es el caso del uso urbano y el uso industrial, explicitado y ejemplificado con lo ocurrido en el Puerto de Santos a comienzos de abril del 2015. Las pérdidas, aún no totalmente contabilizadas, están valuadas en millones de dólares con impactos profundos en la economía regional y en los ecosistemas costeros y terrestres de Santos. Esa incompatibilidad mencionada es aún mayor cuando se trata de industrias catalogadas como "peligrosas" y de barrios que se han asentado de modo espontáneo e ilegal sin ningún tipo de planificación, como es el caso de Paranaguá. La realidad se complejiza más si consideramos que el puerto, principal generador de empleo, es un área donde convive una gran cantidad de trabajadores temporales y permanentes y lo hacen en la zona más amenazada de la ciudad. Debido a que la población expuesta no es estática, al momento de un estudio de riesgos más profundo se deberá contemplar esta tipo de planificación, como es el caso de Paranaguá. La realidad se complejiza más si consideramos que el puerto, principal generador de empleo, es un área donde convive una gran cantidad de trabajadores temporales y permanentes y lo hacen en la zona más amenazada de la ciudad. Debido a que la población expuesta no es estática, al momento de un estudio de riesgos más profundo se deberá contemplar esta oscilación para los trabajos de sensibilización y prevención.

En relación a algunos aspectos metodológicos, cabe destacar que la metodología si bien es simple y no contempla demasiados detalles (topografía, dirección de vientos, etc.) arroja resultados generales muy útiles en clave de planificación territorial. La unión de la metodología de Bosque Sendra y su equipo con la propuesta por la ONU y la ANTT permitió hacer una distinción entre los diferentes niveles de amenaza, según el producto almacenado. Esto significó poder confeccionar un buffer del área amenazada más cercano a la realidad partiendo de diferentes tamaños buffers, sin considerar a todas las empresas por igual.

Este trabajo evidencia la importancia de conocer las amenazas por las que está afectada una ciudad y la relevancia de tener esto en cuenta en los procesos de planificación. Algunas amenazas de origen natural no pueden ser controladas o aminoradas por la sociedad pero, en este caso, las industriales o tecnológicas son un producto netamente social que pueden ser evaluadas, gestionadas y reducidas. Los resultados arrojan el área posiblemente afectada y el siguiente paso, en trabajos futuros, será analizar quienes viven en esa zona y de qué modo lo hacen. 


\section{Referencias}

ACE - Auditoria, Consultoria e Educação Ambiental Ltda., Maxgaia - Consultoria em Gestão Ambiental e do Território Ltda., PRM Serviços de Engenharia de Trânsito e Transportes Ltda. e Soares Neto e Guerios Advogados Associados. Estudo de impacto ambiental. Cattalini Terminais Maritimos S.A. Novo Parque de Tancagem - Ampliação de Área de Armazenamento. 725 p. 2012.

ANTAQ - Agência Nacional de Transportes Aquaviários. Anuário Estadístico, 2014. Disponible en: http://www.antaq. gov.br/anuario. Acceso en mayo, 2015.

ANTT - Agência Nacional de Transportes Terrestres. Resolução $n^{\circ} 420$ de 12 de fevereiro de 2004. Aprova as Instruções Complentares ao Regulamento do Transporte Terrestre de Produtos Perigosos. Disponible en: http//www. antt.gov.br/index.php/content/view/1420/Resolução_420. Acceso en mayo, 2015.

Ayuntamiento de Madrid, Madrid, Banco de datos (2010). Recuperado el 27 de enero, 2015, de: http://www-2.munimadrid.es/CSE6/control/mostrarDatos.

Barbosa, C. C.; Camara, G.; Medeiros, J. S.; Crepani, E.; Novo, E.; Cordeiro, J. P. Operadores Zonais en Álgebra de Mapas e Sua Aplicação a Zoneamento Ecológico-Econômico. In: Simpósio Brasileiro de Sensoriamento Remoto, Santos/SP, 487-500, 1998.

Bosque Sendra, J.; Díaz Castillo, C.; Díaz Muñoz, M, Gómez Delgado M.; González Ferreiro, D.; Rodríguez Espinosa V., Salado García M. Propuesta metodológica para caracterizar las áreas expuestas a riesgos tecnológicos mediante SIG: Aplicación en la ciudad de Madrid. Revista Internacional de Ciencia y Tecnología de la Información Geográfica, 4, 44-78, 2004.

Boulaich, A., Gómez Delgado, M.; Bosque Sendra, J. Evaluación de las fuentes para el estudio de la exposición al riesgo tecnológico derivado de la actividad industrial en la comunidad de Madrid. Boletín de la Real Sociedad Geográfica, 2007.

Cardoso Rodrigues, J. E. Risco tecnológico: uma análise do porto de Vila do Conde como área potencial de ameaça ao vazamento de óleo para comunidades em situação de vulnerabilidade. Dissertação (Mestrado em Geografia) PPGEO - IFCH - UFPA, Belém, 2008.

EIRD - Estrategia Internacional para la Reducción de Desastres. Ginebra, Suiza. Vivir con el Riesgo. Informe mundial sobre iniciativas para la reducción de desastres. 2004. Disponible en: http://www.unisdr.org/files/657_lwrsp. pdf. Acceso en enero, 2015.

Globo G1. Recuperado el 6 de abril, 2015, de: http://g1.globo.com/sp/santos-regiao/noticia/2015/04/bombeiros-ja-usaram-5-bi-de-litros-dagua-em-incendio-fogo-continua.html

IBGE - Instituto Brasileiro de Geografia e Estatística. Rio de Janeiro, IBGE Cidades. (2010). Censo demográfico. Disponible en: http://www.cidades.ibge.gov. Acceso en diciembre, 2014,

Linayo, A. Identificación y tratamiento del riesgo tecnológico urbano de la ciudad de Mérida (Venezuela). ONU. In: Estrategia Internacional para la Reducción de Desastres (UN/EIRD): La gestión del riesgo urbano en América Latina: Recopilación de artículos, p. 173-190. 2009.

ONU - Organización de las Naciones Unidas. Nueva York y Ginebra. Recomendaciones relativas al transporte de mercancías peligrosas. Reglamentación Modelo. Volumen I, decimoctava versión revisada, 2013. Disponible en: http:// www.unece.org/fileadmin/DAM/trans/danger/publi/ unrec/ rev18/Spanish/ST-SG-AC10-1-Rev18_Vol1_s.pdf. Acceso en enero 2015.

PDM - Plano Diretor de Desenvolvimento Integrado de Paranaguá. Fundação da Universidade Federal do Paraná e Universidade Federal do Paraná. Paranaguá/PR., 2006.

PDZPO - Plano de Desenvolvimento e Zoneamento do Porto de Paranaguá. APPA (Administração dos Portos do Paraná), Laboratório de Transporte e Logística - LABTRANS, Florianópolis, 2012.

Poffo, I. R.; Haddad. E.; Minniti, V. Gerenciamento de riscos em Terminais e a minimização de acidentes ambientais envolvendo produtos químicos. In: V Seminário Internacional do Meio Ambiente Marinho - SOBENA. Socied. Brasileira de Engenharia Naval, Rio de Janeiro, RJ. V Seminário Inernacional do Meio Ambiente Marinho - SOBENA, 2005. 
RAMINP. Decreto $n^{\circ}$ 2414/1961, del 30 de noviembre de 1962. España. BOE núm. 292, Madrid p 17259 a 17271, 07 dic. 1961.

Rangel Junior, E. Pós: como evitar explosões. Revista Química e Derivados, 464, 2007.

Soares, C. R. Os Portos de Paranaguá (PR) e Itajaí (SC): análise comparativa das suas relações com as cidades de inserção, da estrutura operacional atual e das condições socioambientais das regiões de entorno. Tese (Doutorado em Geografia), Setor de Ciências da Terra, Universidade Federal de Paraná, Curitiba, Brasil, 2009.
Tonetti, E. L. Potencialidades de adensamento populacional por verticalização das edificações e qualidade ambiental urbana no município de Paranaguá, Paraná, Brasil. Tese (Doutorado em Geografia), Setor de Ciências da Terra, Universidade Federal de Paraná, Curitiba, Brasil, 2011.

Torrisi, D.; Paula, E. V.; Wroblewski, C. A. Evaluación de amenazas tecnológicas en el Puerto de Paranaguá/PR, Brasil. In: Anais do XV Encontro de Geógrafos de América Latina. Havana, 2015. p.140-154. 